\title{
Additives and thermal treatment influence on microstructure of nonferrous alloys
}

\author{
M. Krupiński • B. Krupińska • Z. Rdzawski • \\ K. Labisz • T. Tański
}

Received: 25 November 2014/Accepted: 25 January 2015/Published online: 3 March 2015

(C) The Author(s) 2015. This article is published with open access at Springerlink.com

\begin{abstract}
Although $\mathrm{Zn}$ alloys are a very widely used material, there is a need for investigations concerning the influence of thermal conditions on its microstructure and its properties, which makes it useful for the specific tasks it has to fulfil for mass-produced items manufactured by the metalworking industry, in the automotive industry, as well as in countless electronic components. One of the possibilities is to create finer microstructures and enhance their properties, to change their chemical composition by adding alloying additives, and inoculation using modifiers. So in this paper, investigation results are presented concerning the influence of chosen alloying additives, such as $\mathrm{Sr}, \mathrm{Ce}$ and $\mathrm{Ti}-\mathrm{B}$ on the measured and calculated thermal characteristics and microstructure of zinc alloys with the addition of aluminium and copper. Based on the results on the phase and chemical composition of the cast $\mathrm{Zn}-\mathrm{Al}-\mathrm{Cu}$ alloys, inoculated with $\mathrm{Sr}$ and $\mathrm{Ti}-\mathrm{B}$, no differences were detected in the phase composition of the investigated alloys, owing to changes in cooling rates, which were chosen for the sample cooling process. A small amount of added cerium caused the occurrence of new phases present in the microstructure. Modification of the $\mathrm{Zn}-\mathrm{Al}-\mathrm{Cu}$ alloy precipitates changes in the thermomorphology of the phase and the 'tweed' type changes in the microstructure. Moreover, the addition of cerium causes a decrease in the temperature at the beginning $\left(T_{\mathrm{L}}\right)$ and the end of the solidification, as well as the occurrence of a multicomponent eutectic, which can be detected on the derivative curve.
\end{abstract}

\footnotetext{
M. Krupiński ( $\square)$ · B. Krupińska · Z. Rdzawski · K. Labisz T. Tański

Institute of Engineering Materials and Biomaterials, Silesian University of Technology, Konarskiego Str 18A,

44-100 Gliwice, Poland

e-mail: mariusz.krupinski@polsl.pl
}

Keywords Zinc alloys - Thermo-derivative analysis · Cooling rate $\cdot$ Alloying additives $\cdot$ Latent heat . Inoculation $\cdot$ Multicomponent eutectic

\section{Introduction}

Growing customer demand for components of engineering materials with high mechanical properties and high corrosion resistance is an important reason for extending investigations into improving existing alloys and developing new $\mathrm{Zn}$ alloys with enhanced properties and competitive prices [1-6].

$\mathrm{Zn}$ alloys are used primarily for the manufacture of fine, thin-walled casts, which require high processing precision. These alloys are also characterized by a higher casting speed, providing a ten times greater stability of the crucibles, which makes them very useful for industrial masscasting production $[1,6]$.

In order to improve the mechanical properties of cast alloys, their modifications are often used in addition to heat treatment, which causes morphology changes and a decrease in the interfacial distance of the $\alpha^{\prime}+\eta$ eutectic, and refinement of the microstructure and the dendrite arm spacing, such as $\mathrm{Zn}-\mathrm{Al}$. Currently, strontium and antimony are used as modifiers because they are long-term operating modifiers (Fig. 1; Table 1) [4].

The effect of strontium remains after many re-melting processes, as it enables the production of alloys that were modified directly in the foundries. Increasingly, rare earth metals are also widely used to modify the cast alloys [7-10].

In particular, $\mathrm{Zn}$ alloys with a high $\mathrm{Al}$ content tend to shrink, which is possibly to compensate for the introduction of alloying elements, such as $\mathrm{Sr}, \mathrm{Ca}, \mathrm{Li}, \mathrm{Ti}, \mathrm{Zr}, \mathrm{Sb}, \mathrm{B}$ and rare earth metals. Good castability and filling of the 
Table 1 Quantitative energy-dispersive spectroscopy EDS analysis results of the $\mathrm{ZnAlCu}$ alloy with added $\mathrm{Sr}$, cooled at a rate of $0.09{ }^{\circ} \mathrm{C} \mathrm{s}{ }^{-1}$

\begin{tabular}{llccc}
\hline Analysed point description & \multicolumn{4}{l}{ Mass concentration of the alloy elements/mass\% } \\
\cline { 2 - 5 } & $\mathrm{Al}$ & $\mathrm{Zn}$ & $\mathrm{Cu}$ & $\mathrm{Sr}$ \\
\hline 1 & 47.12 & 48.65 & - & - \\
2 & 5.35 & 70.86 & 11.18 & 4.23 \\
\hline
\end{tabular}

Table 2 Range of element mass concentration

\begin{tabular}{lcccccc}
\hline Alloy description & \multicolumn{6}{c}{ Mass concentration of the elements in the investigated alloys/mass\% } \\
\cline { 2 - 6 } & $\mathrm{Al}$ & $\mathrm{Cu}$ & $\mathrm{Ce}$ & $\mathrm{Sr}$ & $\mathrm{Ti}$ & $\mathrm{B}$ \\
\hline 0.13 mass\% Sr (A) & 8.25 & 0.76 & - & 0.13 & - & - \\
0.04 mass\% Ti, 0.012 mass\% B(D) & 8.96 & 0.94 & - & - & -04 & - \\
(G) & 10.02 & 0.98 & - & - & - \\
0.07 mass\% Ce(K) & 9.6 & 0.78 & 0.07 & - & - \\
\hline
\end{tabular}

Table 3 Quantitative EDS analysis results of the $\mathrm{ZnAlCu}$ alloy with added Ti-B or Ce cooled at a rate of $0.09{ }^{\circ} \mathrm{C} \mathrm{s}-1$

\begin{tabular}{llccc}
\hline Analysed point description & \multicolumn{4}{l}{ Mass concentration of the alloy with Ti-B addition/mass\% } \\
\cline { 2 - 5 } & $\mathrm{Al}$ & $\mathrm{Zn}$ & $\mathrm{Cu}$ & $\mathrm{T}$ \\
\hline 1 in Fig. 2 & 42.86 & 28.60 & 01.19 & 27.35 \\
\hline Analysed area description & Mass concentration of the alloy with Ce addition/mass\% & & $\mathrm{Cu}$ \\
\cline { 2 - 5 } & $\mathrm{Al}$ & $\mathrm{Zn}$ & 01.21 & 11.2 \\
\hline 1 in Fig. 3 & 15.64 & 71.18 & $\mathrm{Ce}$ \\
\hline
\end{tabular}

mould are reduced by the addition of rare earth metals, which, like the addition of titanium, can result in hot cracking [11-13].

By adding $\mathrm{Ti}$, there is a refinement of the $\alpha^{\prime}$ phase dendrites through heterogenic nucleation in the $\mathrm{Al}_{3} \mathrm{Ti}$ and $\mathrm{TiZn}_{3}$ phases [1-3].

Modifiers can be added to the Zn alloys in the form of pure elements or master alloys, such as $\mathrm{Zn}-\mathrm{Al}-\mathrm{Me}$ [1], but the master alloys containing $\mathrm{Al}$ can cause the formation of oxide phases in the alloy, which may interfere with the crystallization process of alloys. The relation between the temperature gradient and the solidification rate variation of the structure around the reinforcing elements has a different nature, depending on whether the particle is considered as a local heat depot with the highest temperature, or whether it acts as resistance to the heat flow. The recorded volatile temperature gradient and, above all, the volatility of the function of time and the location of the analysed area relative to the particle are caused purely by differences in the thermal properties of the components. Volatility of temperature derivatives can cause variability of values, which may involve changes in both amplitude and duration [10-16].

\section{Investigation method}

The effect of chemical composition on the crystallization kinetics, microstructure and properties of the cast $\mathrm{Zn}-\mathrm{Al}-$ $\mathrm{Cu}$ alloys was investigated to determine the optimum $\mathrm{Zn}$ modifiers' addition (Tables 2, 3), in the form of $\mathrm{Sr}, \mathrm{Ti}-\mathrm{B}$ and $\mathrm{Ce}$.

The casts were made in a resistance furnace in chamotte-graphite crucibles. The performed casts were cast into metal moulds. In order to investigate the mass concentrations of alloying elements in the form of $\mathrm{Ti}-\mathrm{B}$ and $\mathrm{Sr}$, a chemical analysis investigation was carried out, in accordance with the ICP OES test procedure, using the ULTIMA 2 Jobin-Yvon device.

In the next step, samples for thermo-derivative analysis were prepared, which were $\varnothing 30 \mathrm{~mm}$ in diameter, with a height of $35 \mathrm{~mm}$. Holes were made in the samples for thermocouples, in the place where a thermal centre for this type of sample geometry could occur. The investigated samples had a mass for this type of geometric dimension of $160 \pm 3 \mathrm{~g}$. The thermo-derivative analysis for the investigated alloys with alloying additives was performed using a graphite crucible, by applying the Universal 


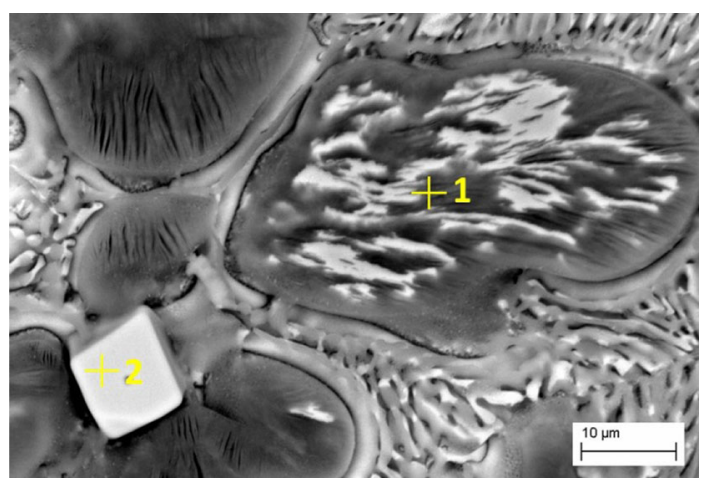

Fig. 1 Microstructure of the cast $\mathrm{ZnAlCu}$ alloy with added $\mathrm{Sr}$, cooled at a rate of $0.09{ }^{\circ} \mathrm{C} \mathrm{s}^{-1}$ (see also Table 1)

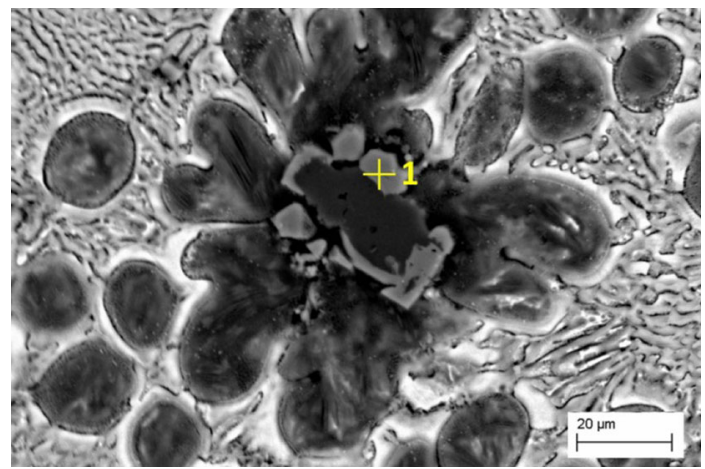

Fig. 2 Microstructure of the cast $\mathrm{ZnAlCu}$ alloy with added $\mathrm{Ti}-\mathrm{B}$, cooled at a rate of $0.09^{\circ} \mathrm{C} \mathrm{s}^{-1}$ (Table 3)

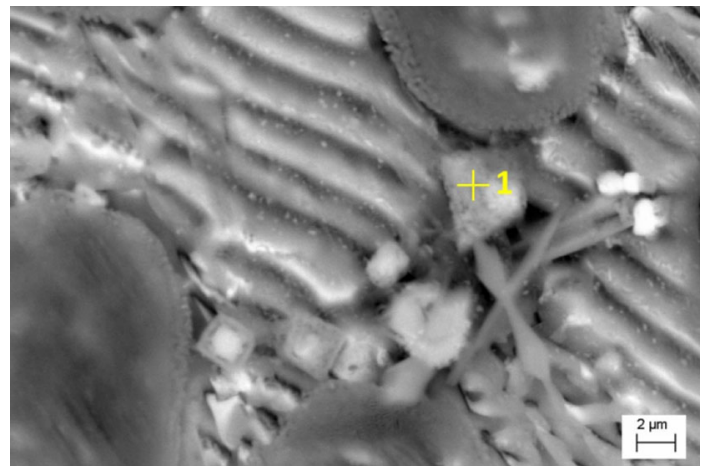

Fig. 3 Microstructure of the cast $\mathrm{ZnAlCu}$ alloy with added $\mathrm{Ce}$, cooled at a rate of $0.09{ }^{\circ} \mathrm{C} \mathrm{s}^{-1}$ (Table 3)

Metallurgical Simulator and Analyser (UMSA), equipped with dedicated software for control and calculation. Temperature measurement was carried out using K-type thermocouples.

Microstructure investigations were performed using a light microscope MEF4A, supplied by Leica, and a scanning electron microscope, Zeiss Supra 35, and were carried

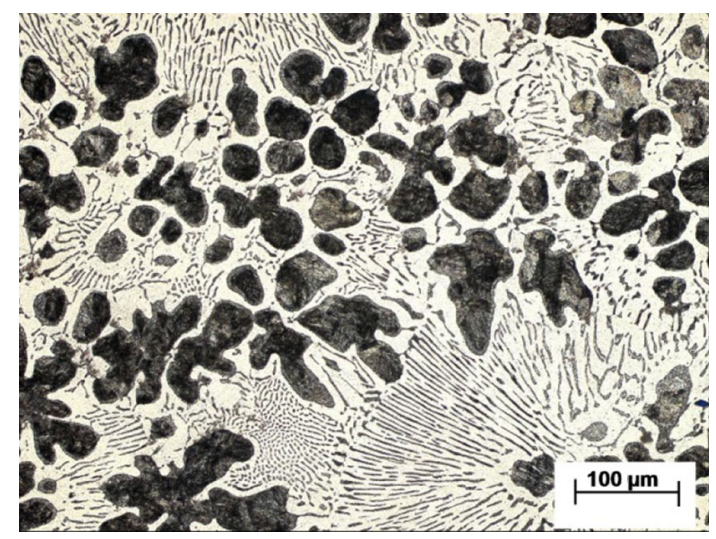

Fig. 4 Microstructure of the $\mathrm{Zn}-\mathrm{Al}-\mathrm{Cu}$ alloy, etched with $10 \% \mathrm{HF}$

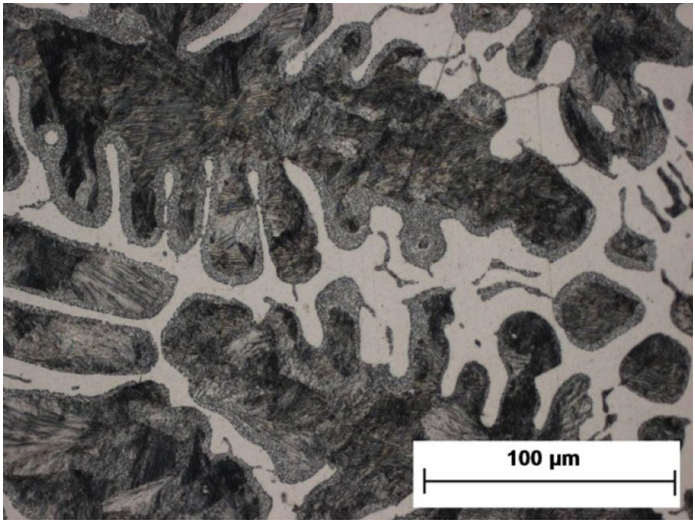

Fig. 5 Microstructure of the $\mathrm{Zn}-\mathrm{Al}-\mathrm{Cu}$ alloy modified with 0.13 mass $\% \mathrm{Sr}(\mathrm{A})$, etched with $10 \% \mathrm{HF}$

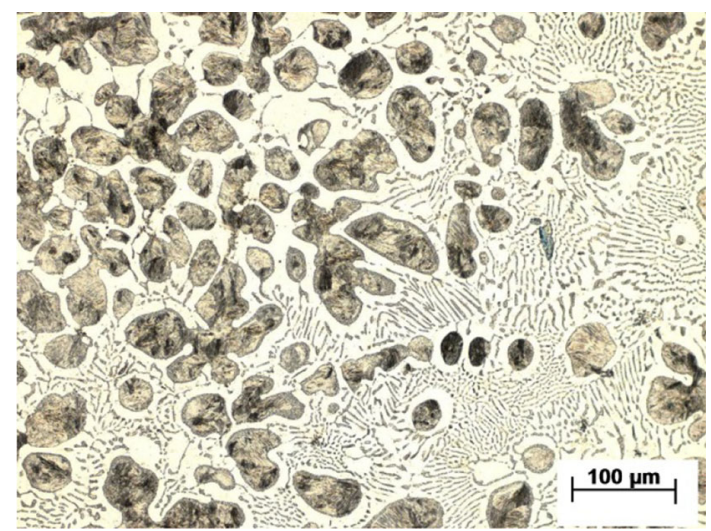

Fig. 6 Microstructure of the $\mathrm{Zn}-\mathrm{Al}-\mathrm{Cu}$ alloy modified with 0.04 mass $\%$ Ti, 0.012 mass\% B(D), etched with $10 \% \mathrm{HF}$

out on properly prepared metallographic samples taken from the melted material in graphite crucibles and cooled at a reasonable cooling rate. The samples were etched with $10 \% \mathrm{HF}$ acid, in order to reveal the microstructure of the alloys. The chemical composition analysis using energy- 


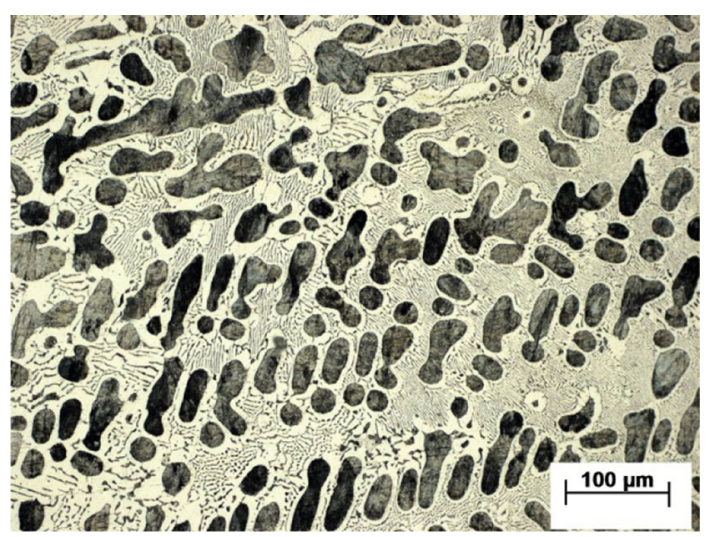

Fig. 7 Microstructure of the $\mathrm{Zn}-\mathrm{Al}-\mathrm{Cu}$ alloy modified with 0.07 mass \% $\mathrm{Ce}(\mathrm{K})$, etched with $10 \% \mathrm{HF}$

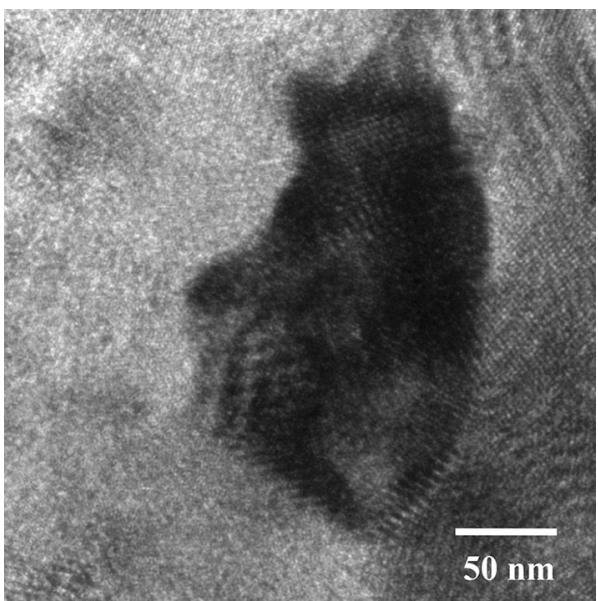

Fig. 8 Ce precipitation in the matrix of the investigated $\mathrm{Zn}-\mathrm{Al}-\mathrm{Cu}$ alloy modified with added cerium, bright-field TEM

dispersive spectroscopy (EDS) of the micro-areas was carried out using a Zeiss Supra 35 scanning electron microscope. Hardness tests were performed using a hardness tester (Zwick ZHR 4150).

For the examination of thin foils, the thin foils were polished using ion milling by the precision ion polishing system (PIPS), with $4 \mathrm{keV}$ at an angle of $5^{\circ}$, and were finally cleaned at $3^{\circ}$ with $3.5 \mathrm{keV}$. Microstructure and phase identification were made on the JEOL 3010CX transmission electron microscope (TEM), at the accelerating voltage of $300 \mathrm{kV}$, using the selected area diffraction method (SAD) for phase investigation.

\section{Investigation results}

The results of the metallographic investigation performed on the light microscope (Figs. 4-7) indicate that the cast

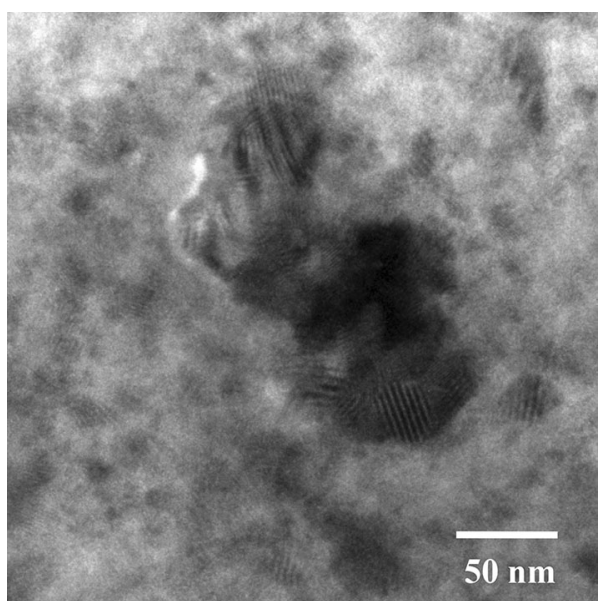

Fig. 9 Coagulated $\mathrm{Ce}$ precipitates with visible areas of crystalline structure in the $\mathrm{Zn}$ alloy modified with added cerium performed in high-resolution TEM

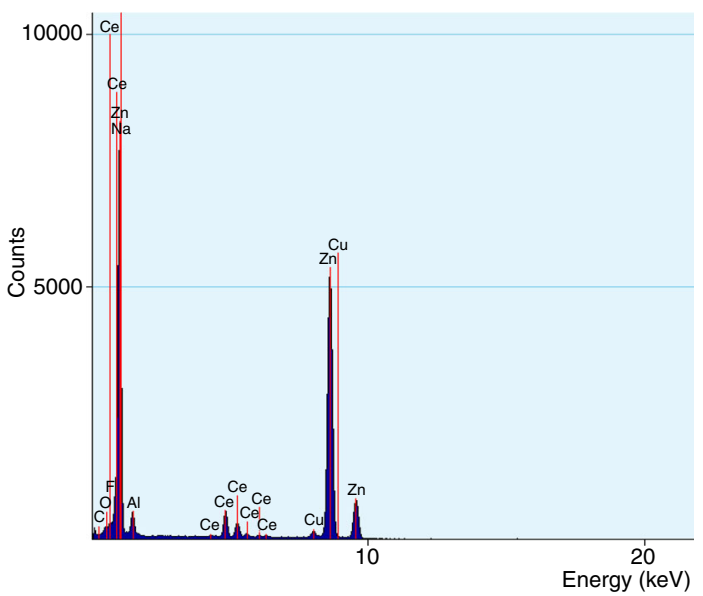

Fig. 10 Point-wise EDS analysis performed using the energydispersive spectrometry X-ray spectrometer, confirming the presence of cerium in the investigated precipitation

zinc alloys with aluminium and copper have a structure consisting of the $\alpha^{\prime}$ solid solution, comprised of the aluminium precipitation, and eutectic grains of $\alpha^{\prime}+\eta$ phase, whose morphology depends on the mass concentration of the modifier in the form of $\mathrm{Sr}, \mathrm{Ce}$ and $\mathrm{Ti}-\mathrm{B}$.

The microstructure of the $\mathrm{Zn}-\mathrm{Al}-\mathrm{Cu}$ alloy is characterized by the globular precipitation of the $\alpha^{\prime}$ phase, whose refinement occurs with an increase in the cooling rate (Fig. 4).

Modification of the $\mathrm{Zn}-\mathrm{Al}-\mathrm{Cu}$ alloy with $\mathrm{Sr}$ causes changes in the morphology of $\alpha^{\prime}$ precipitations, which reveal a dendritic form (Fig. 5), and does not significantly change their size. 


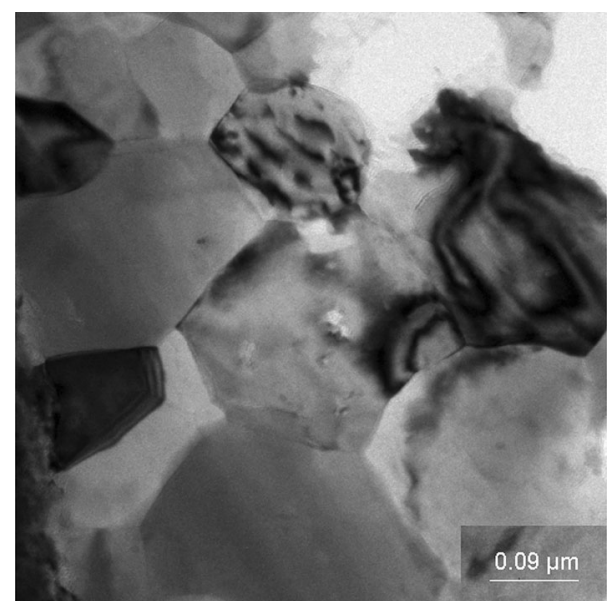

Fig. 11 Structure of the micrograins in the investigated $\mathrm{Zn}-\mathrm{Al}-\mathrm{Cu}$ alloy modified with added cerium, bright-field TEM

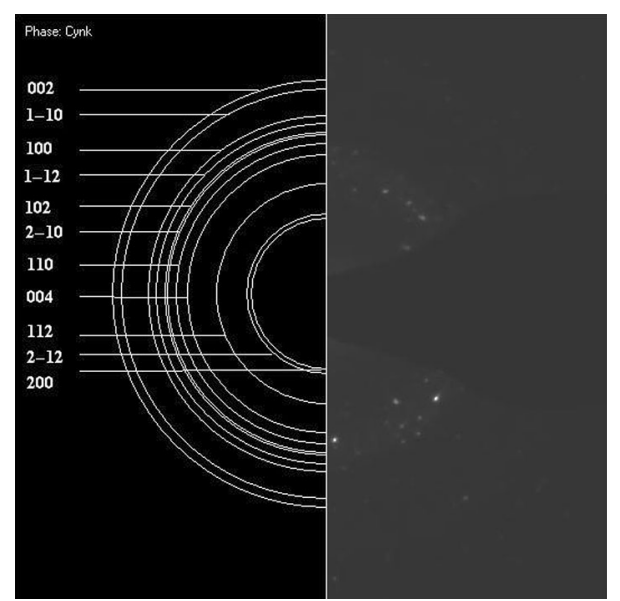

Fig. 12 Diffraction pattern of the polycrystalline area showed in Fig. 11 for the $\mathrm{Zn}-\mathrm{Al}-\mathrm{Cu}$ alloy modified with added cerium, TEM

- Modification with Ti-B does not cause a change in the morphology of phases and eutectics. However, it causes refinement of the $\alpha^{\prime}$ phase and eutectic $\alpha^{\prime}+\eta$ (Fig. 6).

- Modification with Ce causes a change of the morphology of the $\alpha^{\prime}$ phase, which is characterized by a 'tweed' texture (Fig. 7). Modification of rare earth metals also causes the refinement of the microstructure and changes the result dispersion of the surface area and circumference of the alloy precipitations.

The investigations carried out on the TEM, with a high magnification range reaching high-resolution imaging, reveal that atomic planes allow us to confirm the fine-grained polycrystalline structure of the investigated alloy, concerning also the possible Ce phase agglomeration occurring in the $\mathrm{Zn}-\mathrm{Al}$ matrix, within a size range up to $200 \mathrm{~nm}$ (Figs. 8-10). The point-wise EDS analysis was carried out in a micro-area of these precipitations and confirms the

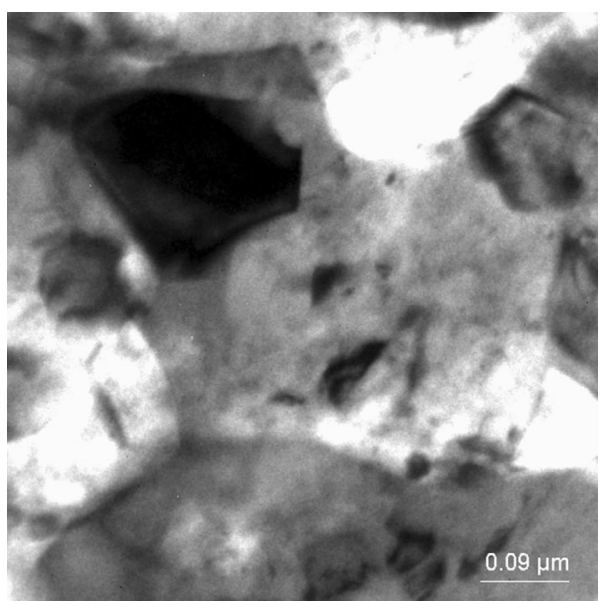

Fig. $13 \mathrm{Zn}_{2} \mathrm{Ce}$ particle in the $\mathrm{ZnAlCu}$ alloy structure modified with added cerium, bright-field TEM

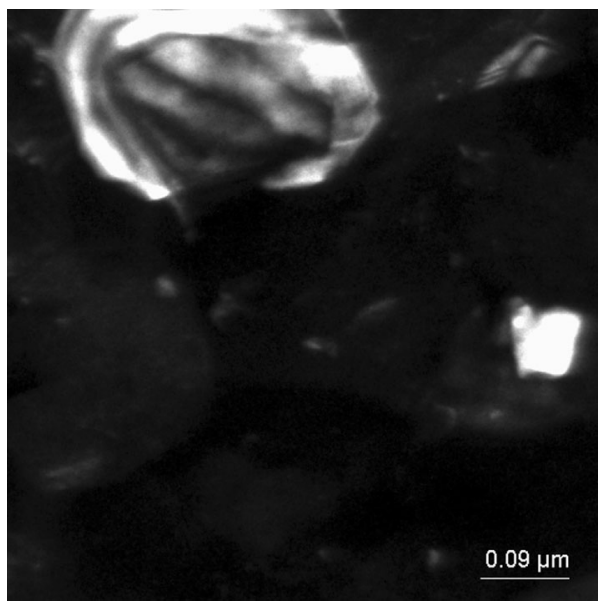

Fig. $14 \mathrm{Zn}_{2} \mathrm{Ce}$ particle in the $\mathrm{ZnAlCu}$ alloy structure modified with added cerium, dark-field TEM

presence of cerium, besides the substrate elements zinc and aluminium. Using SAD diffraction patterns of the polycrystalline $\mathrm{Zn}$ material area, it was possible to identify the $\mathrm{Zn}_{\alpha}$ phase of the investigated material substrate, based on the microstructure consisting of subgrains (Figs. 11, 12). The calculated d-spacing allowed us to identify zinc. However, the d-spacing values show a wider range of values, which can be indices for dissolving cerium in the $\mathrm{Zn}$ matrix. On the diffraction pattern, there are visible rings representing different d-spacing, which could confirm that cerium dissolves in different amounts in zinc, changing the dimensions of the crystalline lattice. The size of the subgrains, in the range between 100 and $400 \mathrm{~nm}$, is presented in the dark-field TEM image (Figs. 13, 14). In Figs. 13 and 14 , the structures of the investigated zinc alloy with cerium are presented, as well as the results of electron diffraction analysis, confirming the presence of the $\mathrm{Zn}_{2} \mathrm{Ce}$ phase, with 


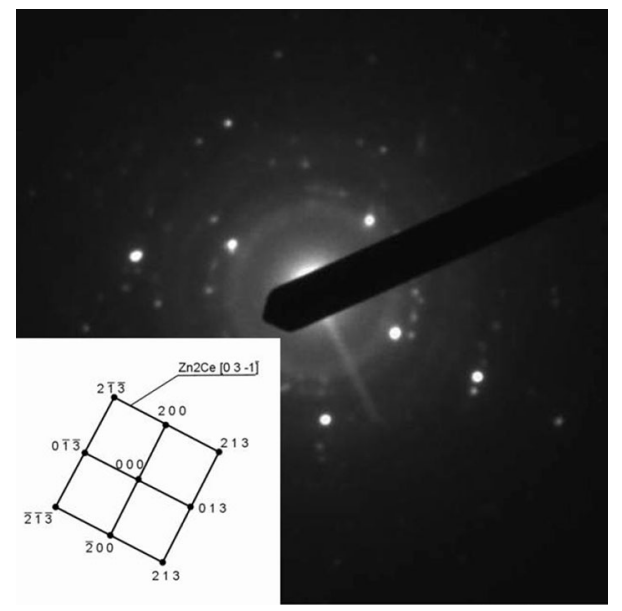

Fig. 15 Diffraction pattern of the area showed in Fig. 13 with the solution confirming the $\mathrm{Zn}_{2} \mathrm{Ce}$ phase

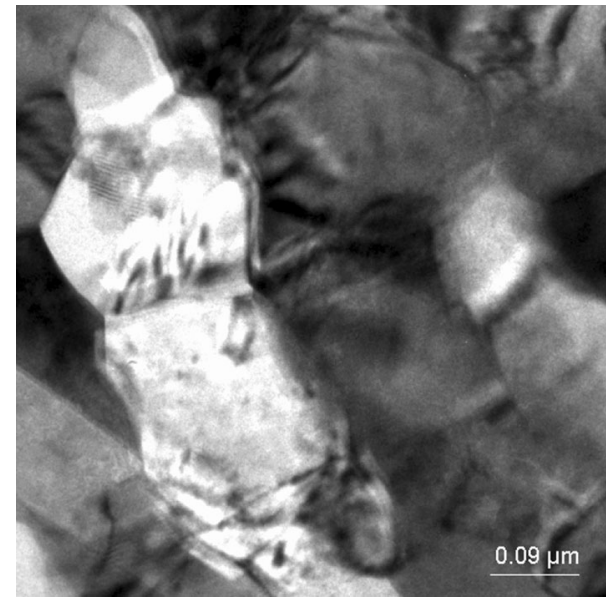

Fig. $16 \mathrm{ZnAlCu}$ alloy structure modified with Ti-B cooled freely with the rate of $0.09{ }^{\circ} \mathrm{C} \mathrm{s}^{-1}$, bright-field TEM

the calculated zone axis [03-1] (Fig. 15), whereas other zone axis measurements do not confirm any crystallographic relationship between the $\mathrm{Zn}$ phase and the $\mathrm{Zn}_{2} \mathrm{Ce}$ phase.

The TEM investigation also reveals a phase with $\mathrm{Ti}$ and B participation. Figures 16 and 17 show the microstructure of the $\mathrm{Zn}$ matrix of the alloy enriched with $\mathrm{Ti} / \mathrm{B}$. In the thin foil investigation, the $\mathrm{Zn}$ structure can be recognized with subgrains of size $0.2 \mu \mathrm{m}$. The transition zone between the grains of a significant difference in dislocation density is also presented in this bright-field image. These zones are characterized by a smooth transition between the zones, with a clearly visible boundary between the area of significant dislocation density and grains of relatively uniform crystalline structure without defects (Fig. 16). The calculated $\mathrm{Zn}$ grain zone axis is measured as [23-1] (Fig. 17). In

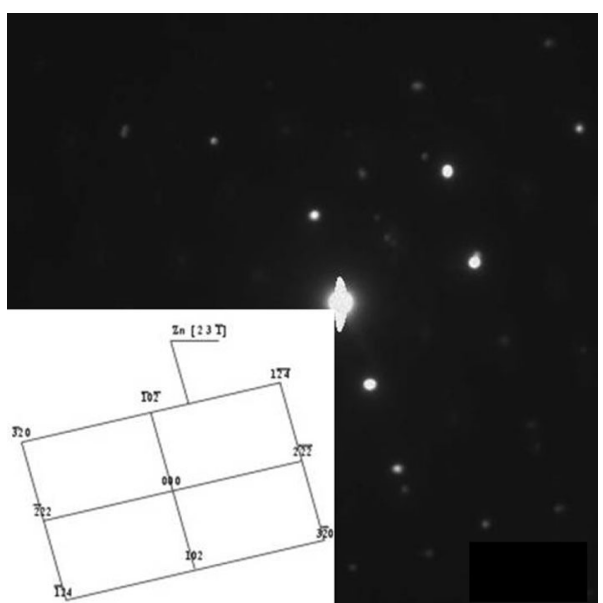

Fig. 17 Diffraction pattern of the eutectic area showed in Fig. 16 with the solution confirming the $\mathrm{Zn}$ phase with the zone axis [23-1], TEM

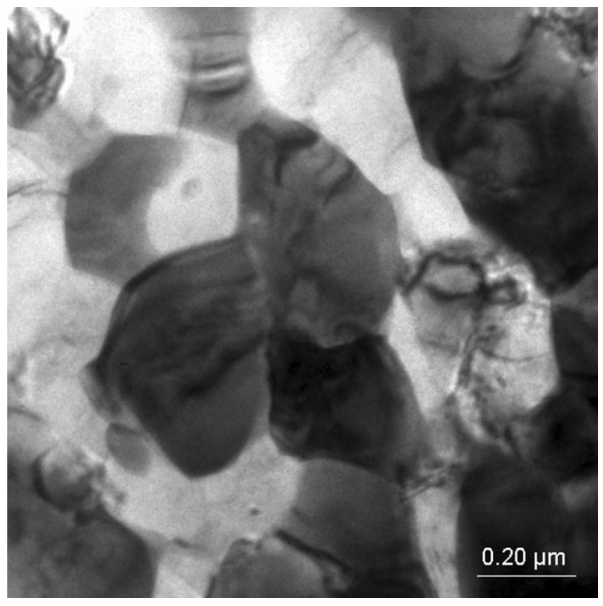

Fig. $18 \mathrm{ZnAlCu}$ alloy structure modified with added Ti-B cooled freely at a rate of $0.09{ }^{\circ} \mathrm{C} \mathrm{s}^{-1}$, bright-field TEM

Figs. 18-20, the determined ( $\mathrm{Al}, \mathrm{Ti}) \mathrm{B}_{2}$ phase discovered in this alloy is presented, with a particle size of ca. $0.4 \mu \mathrm{m}$ and a zone axis of [111].

Representative cooling and crystallization curves of the investigated cast $\mathrm{Zn}-\mathrm{Al}-\mathrm{Cu}$ alloys cooled freely are shown in Figs. 21-24. Analysing the crystallization process based on the obtained cooling curves, it was found that at the temperature $T_{\mathrm{L}}$ starts the $\alpha$ phase nucleation process. On the derivative curve, this appears as a low-sized inflection point $I$ and a temporary decrease in the cooling rate of the alloy. Thermal effects accompanying the nucleation process provide additional heat to the remaining liquid in cases of phase cooling, where the thermal balance of the cooling ingot is negative, as presented on the derivative curves (Figs. 21-24), with the value $\mathrm{d} T / \mathrm{d} t$. In the case of eutectic crystallization, the derivative curve reveals a neutral zero 


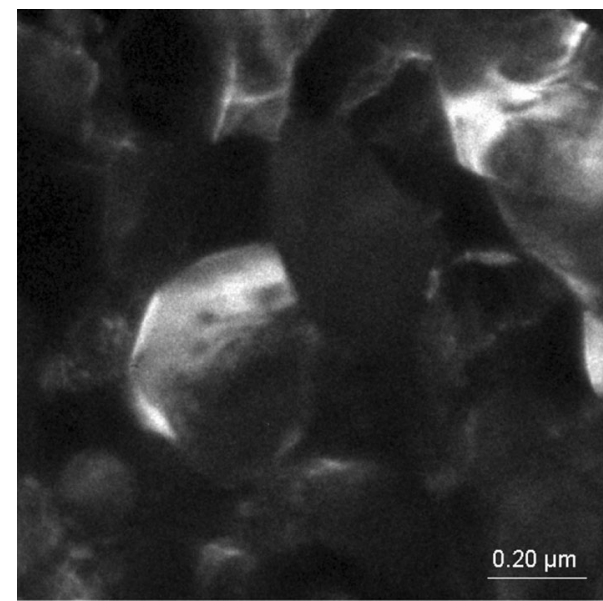

Fig. $19 \mathrm{ZnAlCu}$ alloy structure modified with added Ti-B cooled freely at a rate of $0.09{ }^{\circ} \mathrm{C} \mathrm{s}^{-1}$, dark-field TEM

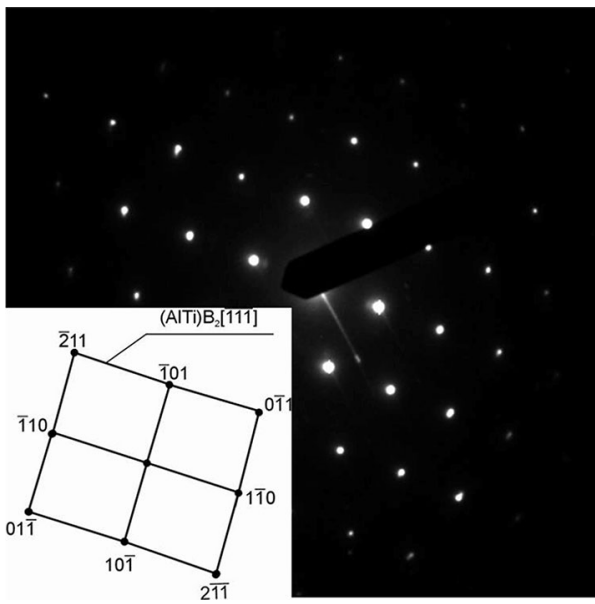

Fig. 20 Diffraction pattern of the eutectic area showed in Fig. 18 with the solution confirming the $(\mathrm{Al}, \mathrm{Ti}) \mathrm{B}_{2}$ phase, TEM

value. In some cases where the heat leaves the crystallized material, the $\mathrm{d} T / \mathrm{d} t$ becomes positive. As seen from the curve, nucleation starts above the steady-state growth temperature. This means that new crystals can form, not only at the first contact of the melt with the cold walls of the mould, but also in the liquid, depending on positive or negative $\mathrm{d} t / \mathrm{d} T$ value. If this value becomes high (several Celsius degree) so refined structure is obtained with decreasing in this value, we get larger grains, than eutecticnear $\mathrm{d} t / \mathrm{d} T=0$, whereas for negative $\mathrm{d} t / \mathrm{d} T$ values in the mould occur precipitations of phases.

The chemical composition of the remaining liquid changes according to the liquidus line on the $\mathrm{Zn}-\mathrm{Al}$ equilibrium diagram. The liquid enriched with more zinc, and after the temperature $T_{\mathrm{E}(\mathrm{Al}+\mathrm{Zn})}$ is achieved, there begins the nucleation process of eutectic $\alpha+\eta$ (point III). Upon

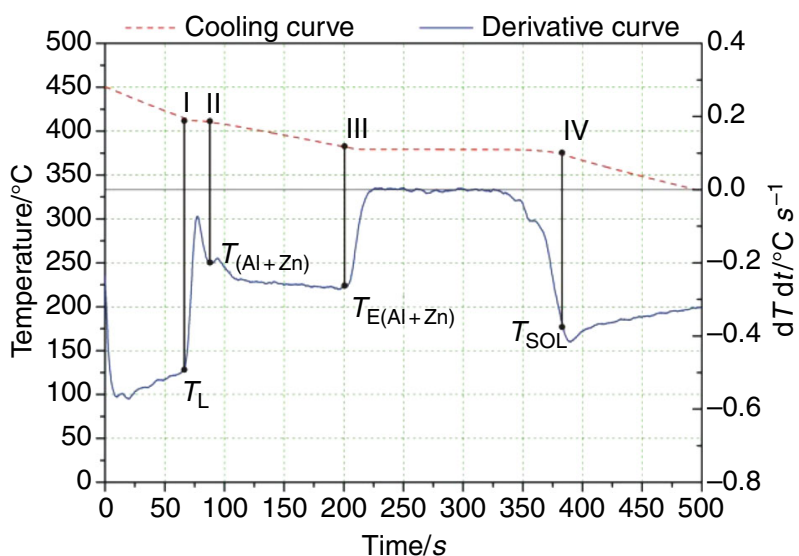

Fig. 21 Cooling curve, crystallization curve of the $\mathrm{Zn}-\mathrm{Al}-\mathrm{Cu}$ (G) alloy cooled at a rate of $0.09^{\circ} \mathrm{C} \mathrm{s}^{-1}$

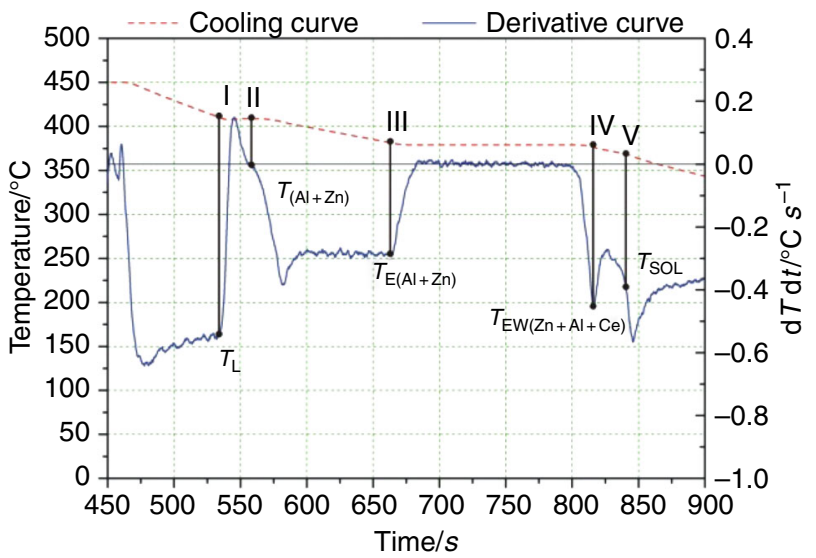

Fig. 22 Cooling curve, crystallization curve of the $\mathrm{Zn}-\mathrm{Al}-\mathrm{Cu}$ alloy with 0.07 mass\% $\mathrm{Ce}(\mathrm{K})$ cooled at a rate of $0.09{ }^{\circ} \mathrm{C} \mathrm{s}^{-1}$

further cooling of the remaining liquid is subcooled and then begins the growth of the eutectic $\alpha+\eta$. Crystallization ends when the alloy reaches the solidus temperature of $T_{\text {Sol }}$ (point $\left.I I I\right)$ (Figs. 21, 23, 24).

In the alloys with added cerium, the cooling of the melt initiates the crystallization of cerium-rich phases, which emit additional crystallization heat, which results in distinct thermal effects detected on the differential curve (point III). Such crystallization begins at the temperature of $T_{\mathrm{EII}(\mathrm{Al}+\mathrm{Zn}+\mathrm{Ce})}$ and continues until the solidus temperature $T_{\text {Sol }}$ (point $I V$ ) is achieved (Fig. 22).

Modification of the $\mathrm{Zn}-\mathrm{Al}-\mathrm{Cu}$ alloy with cerium raises the crystallization temperature of the $\alpha+\eta$ eutectics and lowers the temperature at the end of alloy crystallization $T_{\text {Sol. }}$. This is because the end of crystallization solidifies the multicomponent eutectics, which lowers the solidification temperature owing to the additional crystallization heat which was emitted during cooling. 


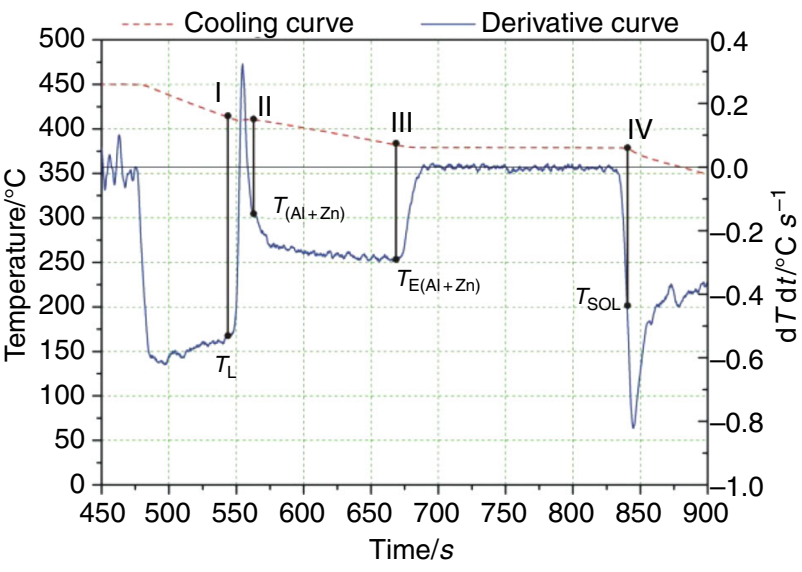

Fig. 23 Cooling curve, crystallization curve of the $\mathrm{Zn}-\mathrm{Al}-\mathrm{Cu}$ alloy with 0.13 mass $\% \mathrm{Sr}$ (A) cooled at a rate of $0.09^{\circ} \mathrm{C} \mathrm{s}^{-1}$

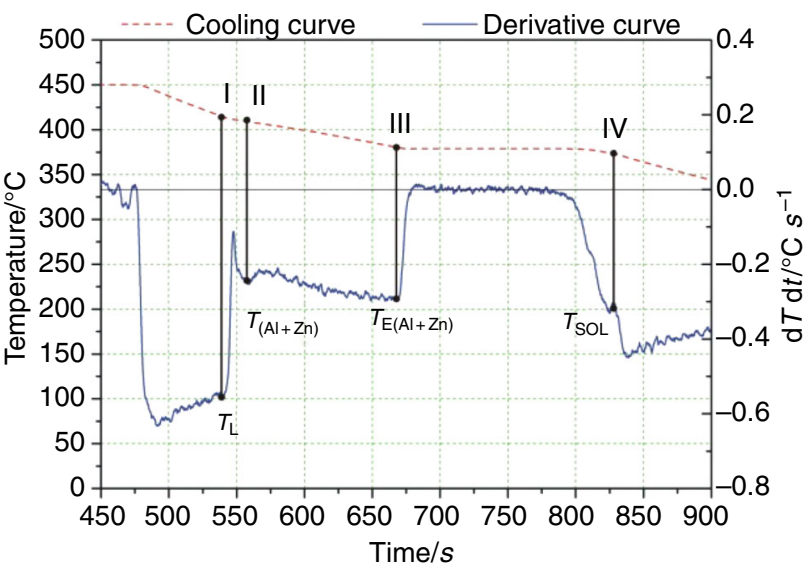

Fig. 24 Cooling curve, crystallization curve of the $\mathrm{Zn}-\mathrm{Al}-\mathrm{Cu}$ alloy with 0.05 mass\% $\mathrm{Ti}-\mathrm{B}(\mathrm{D})$ cooled at a rate of $0.09{ }^{\circ} \mathrm{C} \mathrm{s}^{-1}$

Table 4 Crystallization temperature of the different phases for different types of investigated alloys

\begin{tabular}{lllll}
\hline Alloy type & \multicolumn{4}{l}{ Temperature $/{ }^{\circ} \mathrm{C}$} \\
\cline { 2 - 5 } & $T_{\mathrm{L}}$ & $T_{\mathrm{E}}$ & $T_{\mathrm{EW}}$ & $T_{\text {Sol }}$ \\
\hline $0.09{ }^{\circ} \mathrm{C} \mathrm{s} \mathrm{s}^{-1}$ & & & & \\
$\mathrm{~A}$ & 411.48 & 381.1 & - & 377.61 \\
$\mathrm{D}$ & 412.97 & 380.16 & - & 370.49 \\
$\mathrm{G}$ & 414.55 & 381.2 & - & 372.7 \\
$\mathrm{~K}$ & 409.49 & 404.86 & 376.21 & 368.07 \\
\hline
\end{tabular}

Table 4 shows the crystallization temperature of each phase, and Fig. 25 presents the fraction solid during the crystallization of the individual components of the alloy. Modification of the $\mathrm{Zn}-\mathrm{Al}-\mathrm{Cu}$ alloy does not change the crystallization sequence of the alloy:

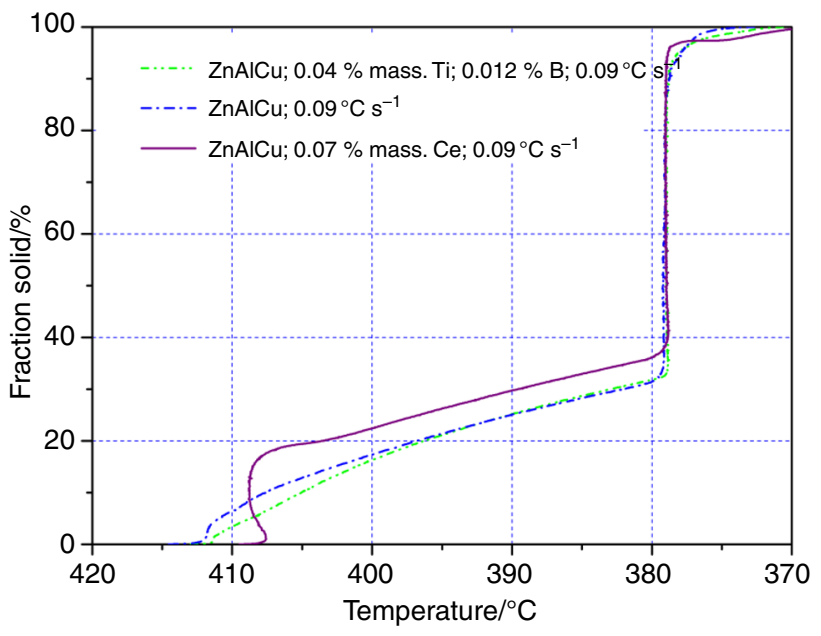

Fig. 25 Fraction solid during the crystallization of particular compounds of the alloy

1. $L \rightarrow \mathrm{Al}$

2. $L \rightarrow \alpha+\eta$

3. $L \rightarrow E(\alpha+\eta)$

Modification of the $\mathrm{Zn}-\mathrm{Al}-\mathrm{Cu}$ alloy with rare earth metals (Ce) alloy causes a change in the crystallization sequence of the alloy

1. $L \rightarrow \mathrm{Al}$

2. $L \rightarrow \alpha+\eta$

3. $L \rightarrow E(\alpha+\eta)$

4. $L \rightarrow E\left(\alpha+\eta+\mathrm{Zn}_{2} \mathrm{Ce} / \mathrm{Zn}_{3} \mathrm{Ce}\right)$

Tables 5-7 present the values of the liquid heat capacity $\mathrm{Cp}_{1}$, the heat capacity and the solid state heat capacity $\mathrm{Cp}_{\mathrm{s}}$. The calculated latent heat of crystallization of the compounds of the investigated alloys and their percentage share are also shown.

The investigated alloys are characterized by a microstructure in which the precipitation of aluminium and $\alpha^{\prime}+\eta$ eutectic was observed (Figs. 4-7). The morphology of the aluminium precipitates and $\alpha^{\prime}+\eta$ eutectic depends on the chemical composition being changed by the introduced additives and the cooling rate. The addition of the Ti-B master alloy gives rise to heterogeneous nucleation (Fig. 2). Strontium precipitation $\mathrm{Al}_{2} \mathrm{Sr}$ is characterized by sharp straight-lined edges (Fig. 1). Modification of the zinc alloy with rare earth metals in the form of cerium causes changes in the microstructure, in which aluminium precipitsation, eutectic $\alpha^{\prime}+\eta$ and $\mathrm{Zn}_{2} \mathrm{Ce}$ phase precipitates are observed, in alloys with cerium (Figs. 13-15), which are components of a multicomponent eutectic. Cerium causes the microstructure to take the form of a 'tweed' structure (Fig. 7).

As a result of the surface element distribution investigations, the presence of major alloying elements included 
Table 5 Latent crystallization heat emitted by the crystallized phases and its percentage share in the total amount of the crystallization heat of the $\mathrm{Zn}-\mathrm{Al}-\mathrm{Cu}$ alloy with 0.13 mass\%. Added $\mathrm{Sr}(\mathrm{A})$ cooled at a rate of $0.09{ }^{\circ} \mathrm{C} \mathrm{s}^{-1}$

\begin{tabular}{lccr}
\hline Liquid heat capacity $\mathrm{Cp}_{\mathrm{l}} / \mathrm{J} \mathrm{g}^{-1}{ }^{\circ} \mathrm{C}^{-1}$ & Solid state heat capacity $\mathrm{Cp}_{\mathrm{s}} / \mathrm{J} \mathrm{g}^{-1}{ }^{\circ} \mathrm{C}^{-1}$ & Sample mass/g \\
\hline 0.5289 & \multicolumn{2}{c}{0.44078} & 153.04 \\
\hline Reaction & Latent crystallization heat & Percentage fraction/\% \\
\cline { 2 - 4 } & Samples/J & Unitary sample mass/J g & \\
\hline $\mathrm{L} \rightarrow \mathrm{Al}$ & 305.62 & 1.99 & 3.67 \\
$\mathrm{~L} \rightarrow \alpha+\eta$ & $2,103.54$ & 13.75 & 25.93 \\
$\mathrm{~L} \rightarrow \mathrm{E}_{(\alpha+\eta)}$ & $5,242.15$ & 34.25 & 70.40 \\
Total & $7,651.31$ & 49.99 & 100 \\
\hline
\end{tabular}

Table 6 Latent crystallization heat emitted by the crystallized phases and its percentage share in the total amount of the crystallization heat of the $\mathrm{Zn}-\mathrm{Al}-\mathrm{Cu}$ alloy with 0.05 mass\% added $\mathrm{Ti}-\mathrm{B}(\mathrm{D})$ cooled at a rate of $0.09{ }^{\circ} \mathrm{C} \mathrm{s}^{-1}$

\begin{tabular}{lccr}
\hline Liquid heat capacity $\mathrm{Cp}_{\mathrm{l}} / \mathrm{J} \mathrm{g}^{-1}{ }^{\circ} \mathrm{C}^{-1}$ & Solid state heat capacity $\mathrm{Cp}_{\mathrm{s}} / \mathrm{J} \mathrm{g}^{-1}{ }^{\circ} \mathrm{C}^{-1}$ & Sample mass/g \\
\hline 0.5304 & \multicolumn{2}{c}{0.442} & 152.36 \\
\hline Reaction & Latent crystallization heat & Percentage fraction/\% \\
\cline { 2 - 4 } & Samples/J & Unitary sample mass/J g & 4.67 \\
\hline $\mathrm{L} \rightarrow \mathrm{Al}$ & 382.41 & 2.51 & 25.57 \\
$\mathrm{~L} \rightarrow \alpha+\eta$ & $2,069.74$ & 13.58 & 69.76 \\
$\mathrm{~L} \rightarrow \mathrm{E}_{(\alpha+\eta)}$ & $5,091.62$ & 33.42 & 100 \\
Total & $7,543.77$ & 49.51 & \\
\hline
\end{tabular}

Table 7 Latent crystallization heat emitted by the crystallized phases and its percentage share in the total amount of the crystallization heat of the $\mathrm{Zn}-\mathrm{Al}-\mathrm{Cu}$ alloy, with 0.07 mass\% $\mathrm{Ce}(\mathrm{K})$ cooled at a rate of $0.09{ }^{\circ} \mathrm{C} \mathrm{s}^{-1}$

\begin{tabular}{lccr}
\hline Liquid heat capacity $\mathrm{Cp}_{\mathrm{l}} / \mathrm{J} \mathrm{g}^{-1}{ }^{\circ} \mathrm{C}^{-1}$ & Solid state heat capacity $\mathrm{Cp}_{\mathrm{s}} / \mathrm{J} \mathrm{g}^{-1}{ }^{\circ} \mathrm{C}^{-1}$ & Sample mass/g \\
\hline 0.5289 & \multicolumn{2}{c}{0.44076} & 152.18 \\
\hline Reaction & Latent crystallization heat & Percentage fraction/\% \\
\cline { 2 - 4 } & Samples/J & Unitary sample mass/J g & \\
\hline $\mathrm{L} \rightarrow \mathrm{Al}$ & 281.27 & 1.85 & 3.41 \\
$\mathrm{~L} \rightarrow \alpha+\eta$ & $2,567.55$ & 16.87 & 31.86 \\
$\mathrm{~L} \rightarrow \mathrm{E}_{(\alpha+\eta)}$ & $4,596.43$ & 30.21 & 62.02 \\
$\mathrm{~L} \rightarrow \alpha+\eta+\mathrm{Ce}$ & 188.26 & 1.24 & 2.71 \\
Total & $7,633.51$ & 50.17 & 100 \\
\end{tabular}

in the investigated cast alloys $\mathrm{Zn}-\mathrm{Al}-\mathrm{Cu}$ was revealed on the example of modification of Sr (Fig. 1).

Research using the EDS techniques made it possible to evaluate the differences in the qualitative and quantitative chemical compositions of selected micro-areas of the sample.

A decreasing concentration gradient of aluminium precipitates $\alpha^{\prime}$ was found in the direction of the $\alpha^{\prime}+\eta$ eutectic, with the dissolution of copper in eutectic as a phase component, depending on the chemical composition and the applied cooling rate (Figs. 21-24).

The morphology of the phase components of the investigated alloys depends on the number of nuclei formed in the initial stage of crystallization and the crystallization rate of the alloy. The driving force of the nucleation process is the degree of undercooling of the liquid and the 
amount of heterogeneous nucleation of crystallization in the (Al,Ti)B $B_{2}$ (Figs. 18-20). The greater the undercooling of the liquid, the more the nucleation, which, after reaching a critical value, increases as the crystal phase of $\alpha$. At the same time, a greater degree of undercooling leads to a reduction in the critical embryo.

Changes in the cooling rate and the modification of the investigated zinc alloys, using strontium, titanium and boron, compared to the alloy without modification, results in a partial modification of the microstructure of the eutectic $\alpha^{\prime}+\eta$, which is confirmed by the metallographic examination of the structure, and the changes recorded in the thermo-derivative analyse diagrams (Figs. 21, 24). Cerium modification changes the crystallization kinetics visible on the derivative curves, obtained by crystallization of the multicompound eutectics (Fig. 22), varying the undercooling of the alloy and the temperature shift of the beginning and the end of the melt crystallization (Table 4).

\section{Conclusions}

Based on the presented results, the following conclusions can be stated:

1. The addition of a low-amount cerium of the alloy, not exceeding $0.07 \mathrm{wt} \%$, causes a change in the temperature of the $\alpha$ phase nucleation. It also causes temperature decreases in the $\alpha$ phase nucleation and at the end of alloy crystallization. The addition of cerium also causes multiple eutectic crystallization.

2. Modification of the alloy by the addition of rare earth metals causes changes in the morphology of the microstructure, from dendritic to a 'tweed' microstructure, and changes the morphology of eutectic $\alpha^{\prime}+\eta$ as a result of changes in the size and the distance between the plates. These changes are recorded and presented in the derivative curves, thereby changing the level of undercooling of the alloy. Structural changes caused by changes in the cooling rate and the chemical composition have a direct impact on the mechanical and functional properties of alloys. In each case, the alloying elements cause an increase in mechanical properties, at least on a similar level to the unmodified alloy.

3. In the structure of the investigated alloy with boron addition beside the eutectic $Z n-A l$ structure, there is confirmed also the occurrence of fine-grained microstructure with crystallite/subgrain size of up to approximately $200 \mathrm{~nm}$.

4. In the Ti/B-enriched alloy, the presence of the $(\mathrm{Al}, \mathrm{Ti}) \mathrm{B}_{2}$ phase was confirmed, with the size of
$0.4 \mu \mathrm{m}$, proved by selected area electron diffraction with the zone axis of the $\mathrm{Zn}$ phase [111].

5. As it can be seen in the fraction solid diagram, the addition of cerium has significant influence on the solidification nature of the alloy. In particular, it causes a higher solid material share at the same temperature compared to TiB-alloyed $\mathrm{Zn}$ alloy and the $\mathrm{Zn}$ alloy without modification. In this way, an undercooling of the alloy can be achieved beside the classical temperature influence at a higher cooling rate, which can be important in the production process where the thermal influence could be shortened with only a very small addition of TiB.

6. Ce particularly lowers the temperature of the begin$\operatorname{ning}\left(T_{\mathrm{L}}\right)$ and end of the solidification $T_{\text {Sol }}$. There is an additional peak on the thermo-analysis curve, which only occurs for the alloys with cerium. This is unknown in the literature, but could help to resolve the influence of this addition on the thermal characteristics of such types of engineering materials.

Acknowledgements This research was financed partially within the framework of the Scientific Research Project No. 2640/B/T02/2011/ 40 headed by Dr Beata Krupińska.

Open Access This article is distributed under the terms of the Creative Commons Attribution License which permits any use, distribution, and reproduction in any medium, provided the original author(s) and the source are credited.

\section{References}

1. Krajewski W. Research of phase transformation in high-aluminium zinc foundry alloys modified by Ti addition. Praktische Metallographie - Practical Metallography. 1999; Special Issue 30:9-11.

2. Górny Z, Sobczak J. Non-ferrous metals based novel materials in foundry practice. Cracow: ZA-PIS; 2005.

3. Krajewski W. DTA examinations of the solidification course of medium-aluminium zinc alloys modified with Ti. Metall Foundry Eng. 2000;26(2):143-7.

4. Krupiński M, Krupińska B, Labisz K, Rdzawski Z, Borek W. Influence of cooling rate on crystallisation kinetics on microstructure of cast zinc alloys. J Therm Anal Calorim. 2014;118(2):1361-7.

5. Krupińska B, Labisz K, Rdzawski Z. Light and electron microscope investigations of cast $\mathrm{Zn}-\mathrm{Al}$ alloys. Arch Mater Sci Eng. 2012;55(1):29-36.

6. Zhu YH. Phase transformations of eutectoid $\mathrm{Zn}-\mathrm{Al}$ alloys. J Mater Sci. 2001;36:3973-80.

7. Zhu YH, Hernandez RM. Banos L, based alloy. J Mater Sci. 1999;34:3653-8.

8. Dobrzański LA, Krupiński M, Labisz K, Krupińska B, Grajcar A. Phases and structure characteristics of the near eutectic $\mathrm{Al}-\mathrm{Si}-\mathrm{Cu}$ alloy using derivative thermo analysis. Mater Sci Forum. 2010;638-642:475-80.

9. Dobrzanski LA, Maniara R, Sokolowski J, Kasprzak W, Krupinski M, Brytan Z. Applications of the artificial intelligence methods for modeling of the ACAlSi7Cu alloy crystallization process. J Mater Process Technol. 2007;192:582-7. 
10. Krupińska B, Labisz K, Rdzawski Z. Crystallisation kinetics of the $\mathrm{Zn}-\mathrm{Al}$ alloys modified with lanthanum and cerium. J Achiev Mater Manuf Eng. 2011;46(2):154-60.

11. Krupińska B, Dobrzański LA, Rdzawski Z, Labisz K. Cooling rate influence on microstructure of the $\mathrm{Zn}-\mathrm{Al}$ cast alloy. Arch Mater Sci Eng. 2010;43(1):13-20.

12. Krupińska B, Labisz K, Dobrzański LA, Rdzawski Z. Crystallisation kinetics of $\mathrm{Zn}$ alloys modified with $\mathrm{Ce}, \mathrm{La}, \mathrm{Sr}, \mathrm{Ti}, \mathrm{B}$. J Achiev Mater Manuf Eng. 2010;42(1/2):50-7.

13. Konieczny J, Dobrzański LA, Labisz K, Duszczyk J. The influence of cast method and anodizing parameters on structure and layer thickness of aluminium alloys. J Mater Process Technol. 2004;157-158:718-23.
14. Rusz S, Cizek L, Salajka M, Tylsar S, Kedron J, Michenka V, Donic T, Hadasik E, Klos M. Ultrafine grain refinement of AlMn1Cu and AZ31 alloys by SPD process. Arch Metall Mater. 2014;59(1):359-64.

15. Tański T, Labisz K, Dobrzańska-Danikiewicz AD, Sękala A. Strategic position of casting aluminium alloys and leading technologies of their manufacturing. Solid State Phenom. 2015;220-221:577-82.

16. Chen TJ, Hao Y, Sun J, Li YD. Effects of Mg and RE additions on the semi solid microstructure of a zinc alloy ZA27. Sci Technol Adv Mater. 2003;4:495-502. 